\title{
Establishing a psychosomatic clinic in a low resource setting: Process, challenges, and opportunities
}

\author{
Vikas Menon, Siddharth Sarkar', Shijo Thomas \\ Department of Psychiatry, Jawaharlal Institute of Post Graduate Medical Education and Research, Puducherry, ${ }^{1}$ Department of Psychiatry and \\ NDDTC, All India Institute of Medical Sciences, New Delhi, India
}

\begin{abstract}
Background: Specialty psychosomatic clinics are a felt need in low- and middle-income countries, but its benefits and challenges have not been reported so far. Aims: To describe the process, challenges, and opportunities that we encountered in setting up a specialty psychosomatic clinic at a government medical college in South India. Methods: The biweekly psychosomatic clinic was located in the Department of Psychiatry and manned by a multimodal team. Structured questionnaires were used to evaluate all patients. All psychiatric diagnoses were made as per International Classification of Diseases-10, clinical descriptions and diagnostic guidelines. Management comprised both pharmacotherapy and psychotherapeutic interventions. Results: A total of 72 patients registered for services in the $1^{\text {st }}$ year of the clinic. The mean age of the sample was 36.6 years (range $14-60$ years). A median of 2 years and 19 visits to various care providers had elapsed before their visit to the clinic. The index contact was a general practitioner in the majority of cases though an overwhelming majority (95.6\%) had also sought specialist care. The most common diagnostic cluster was the somatoform group of disorders $(50.0 \%)$. Antidepressants were the most commonly prescribed medications (70.6\%). Conclusion: The specialty psychosomatic clinic provided better opportunities for a more comprehensive evaluation of people with medically unexplained symptoms and better resident training and focused inter-disciplinary research. It describes a scalable model that can be replicated in similar resource constrained settings.
\end{abstract}

Key words: Challenges, clinic, medically unexplained symptoms, opportunities, psychosomatic

\section{Introduction}

Clinicians commonly encounter patients with physical symptoms that lack a sufficient organic basis..$^{[1]}$ Often, unclear and overlapping terms such as atypical, functional, nonorganic, somatoform, and psychogenic are used to label them. Most of these are seen to have a pejorative connotation and end up doing more harm than good to the patient as physicians become very dismissive in their dealings with such patients. ${ }^{[2]}$ The

\section{Address for correspondence:}

Dr. Vikas Menon, Department of Psychiatry, Jawaharlal Institute of Post Graduate Medical Education and Research, Puducherry - 605 006, India.

E-mail: drvmenon@gmail.com

\begin{tabular}{|l|l|}
\hline \multicolumn{2}{|c|}{ Access this article online } \\
\hline Quick Response Code: & Website: \\
\hline & www.ruralneuropractice.com \\
\cline { 2 - 3 } & \\
\hline & \\
\end{tabular}

term "medically unexplained symptoms" (MUS) is now preferred for these complaints as they do not imply psychological causation and are more likely to be acceptable to the sufferers. ${ }^{[3]}$ They are often associated with steep healthcare costs and lower economic productivity. ${ }^{[4-7]}$ MUS has many intrinsic features such as possible neural sensory amplification and preoccupation with the meaning of symptoms, which make it an attractive model for understanding and treating psychosomatic conditions. ${ }^{[8]}$ In India, the management of people with MUS poses unique issues as the extant medical training system does not produce an exclusive stream of primary care practitioners who look after most MUS patients like in the West. ${ }^{[9-11]}$ Hence,

This is an open access article distributed under the terms of the Creative Commons Attribution-NonCommercial-ShareAlike 3.0 License, which allows others to remix, tweak, and build upon the work non-commercially, as long as the author is credited and the new creations are licensed under the identical terms.

For reprints contact: reprints@medknow.com

How to cite this article: Menon V, Sarkar S, Thomas S. Establishing a psychosomatic clinic in a low resource setting: Process, challenges, and opportunities. J Neurosci Rural Pract 2016;7:171-5. 
most of their management is left to specialist care that is obviously a strain on the meagre resources. Poor rates of completed psychiatry referrals, rejection of physician reassurance and normalizing explanations, and conflicting models of understanding the problems are some of the challenges in managing MUS. ${ }^{[12-14]}$ Evidence from randomized controlled trials, mostly conducted in primary care settings, reveal that multi-dimensional strategies involving principles of cognitive-behavioral therapy, targeted pharmacotherapy, and patient-centered management can be cost effective, and, at the same time, increase patient satisfaction and health outcomes. ${ }^{[3]}$ If all these required services are available in a single place, it may logically enhance follow-up rates, patient satisfaction and reduce redundant consultations. In this study, we aim to describe our novel attempt to set up a psychosomatic clinic, in a tertiary care hospital in South India, with the goal of providing comprehensive services to patients with MUS. The practical challenges and opportunities that emerged in this process are elaborated so that similar initiatives can be encouraged. We also report the patient profiles and their pathways to care.

\section{Methods}

\section{Context of the clinic}

This Psychosomatic Clinic was established in the Department of Psychiatry of a state-funded teaching cum Tertiary Care Hospital in South India. The hospital has all clinical and paraclinical departments functioning within its own premises. Any patient can just walk-in and avail all the services without any prior appointment. Treatment is heavily subsidized, and most of the investigations and many basic medications are dispensed free of cost. The majority of patients who avail the services belong to lower socioeconomic strata. The Department of Psychiatry has a good consultation-liaison service and gets a fair number of cases referred from other departments. Many of the patients are referred for somatic complaints for which no commensurate physical diagnosis could be entertained. Since many of them are unhappy at being sent to a psychiatrist and also because of high attrition levels, the need was felt for a separate clinic to specifically address the complex concerns of patients with psychosomatic problems. Initially, it was decided to focus upon people presenting with MUS as they formed the bulk of psychosomatic referrals. Prior to the inception of the clinic, letters were sent to all clinical departments sensitizing them to its nature and scope to ensure prompt referrals.

\section{Structure of the clinic}

The psychosomatic clinic was spaced in the department of psychiatry for reasons of feasibility. The workflow of the clinic is shown in Figure 1. It was planned as a biweekly clinic, with 1 day of the week dedicated for detailed assessment of new cases and the other day for follow-up of the registered cases. The team manning the clinic comprised a consultant psychiatrist, one senior resident (equivalent to registrar), one junior resident trainee (equivalent to PG registrar) posted on rotation, a clinical psychologist as well as a psychiatric social worker. The consultant supervised the overall functioning of the clinic and discussed the case workups. The senior resident was involved in providing clinical care and managing administrative issues. The junior resident did detailed assessments and carried out psychotherapeutic interventions in selected cases. As per International Classification of Diseases (ICD)-10, clinical descriptions and diagnostic guidelines, ${ }^{[15]}$ and formulation of management plan, allotment of diagnosis was done after discussion with the consultant psychiatrist. The clinical psychologist provided structured psychotherapeutic interventions for cases, and psychiatric social worker attended to psychosocial issues if any.

\section{Assessment and management}

The patients who were referred to Department of Psychiatry with primarily somatic complaints were screened by a senior resident, and an appointment was given for further detailed assessment that was conducted in a single day using a structured questionnaire. The first part of the questionnaire covers basic demographic and clinical details. Subsequently, several-structured instruments were used to assess various parameters such as explanatory models of illness, pathways to care, psychological morbidity, social support, coping, and quality of life. The pathway of care was recorded using a specially designed questionnaire to explore the sequence

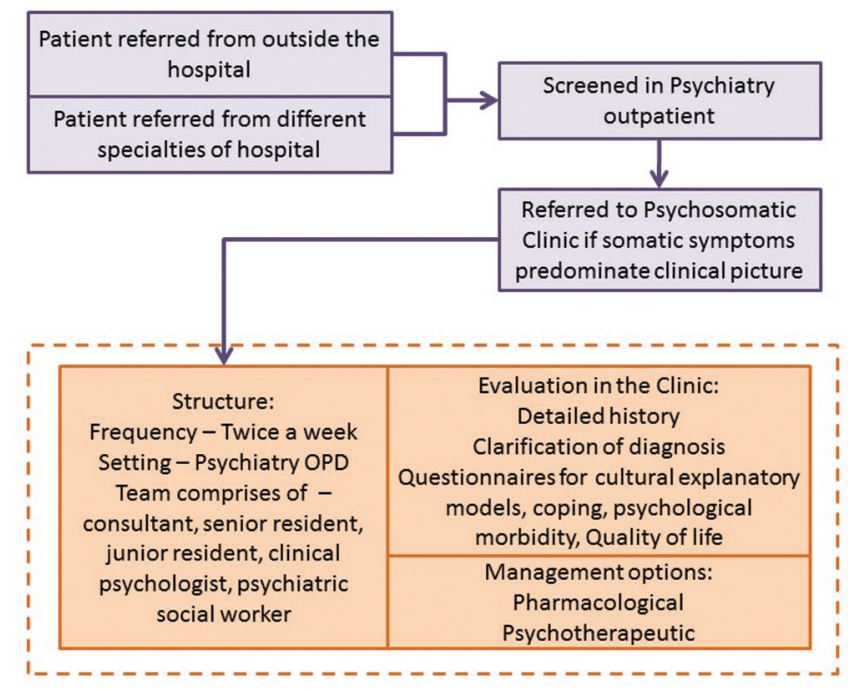

Figure 1: Workflow of the psychosomatic clinic 
of healthcare providers accessed prior to being evaluated in the clinic [Appendix 1]. The questionnaire elicited the details about the first contact (year and number of visits), the sequence of accessing various healthcare providers, and source of referral to the psychiatry department. It was tested for content validity by three subject experts, each with more than 7 years of experience in the field. Subsequently, its inter-rater reliability was tested in a small sample $(n=15)$ of subjects and found to be adequate (Cohen's Kappa $=0.73, P<0.001$ ). To reduce recall bias, information was also collected from the informant and medical records wherever available. A detailed elaboration of all the other instruments used in the clinic is beyond the scope of this paper.

The average assessment time for a single patient was $45 \mathrm{~min}$. After detailed assessment of every patient, the case was discussed with the consultant following whom an ICD-10 diagnosis was allotted and further management plan drawn up. Management comprised both pharmacological and psychotherapeutic interventions. Psychotherapy was delivered by clinical psychologists and psychiatry residents. Regular follow-ups were advised to keep the patient in the treatment loop.

\section{Data analysis and synthesis}

Data were analyzed using SPSS for Windows, version 16.0 (SPSS Inc., Chicago IL, USA). The analysis was conducted for the patients enrolled in the clinic in the $1^{\text {st }}$ year of its existence (January 2014 to December 2014). The present paper aims to report the demographic and clinical profile of the sample and their pathways to care. The analysis was mainly descriptive in nature, and inferential statistics was not carried out. Missing value imputation was not done, and the analysis was conducted with the available data. The various opportunities and challenges stemming from the establishment of this psychosomatic clinic were synthesized.

\section{Results}

\section{Demographic characteristics and pathways of care}

During the $1^{\text {st }}$ year of the clinic, 72 patients were registered in the clinic. The demographic characteristics of the patients are shown in Table 1 . The mean age of the sample was 36.6 years with a range of $14-60$ years. Men slightly outnumbered women at the clinic. The majority of the patients were married, educated up to $10^{\text {th }}$ grade, employed, and belonged to a nuclear family.

The pathway of care data was available for 68 patients (94.4\% of the sample) and is shown in Table 2.
Table 1: Baseline characteristics of patients $(n=72)$

\begin{tabular}{|c|c|}
\hline Variable & $\begin{array}{c}\text { Frequency (\%) } \\
\text { or mean (SD) }\end{array}$ \\
\hline Age in years & $36.6( \pm 10.3)$ \\
\hline \multicolumn{2}{|l|}{ Gender } \\
\hline Male & $39(54.2)$ \\
\hline Female & $33(45.8)$ \\
\hline \multicolumn{2}{|l|}{ Marital status } \\
\hline Currently married & $55(76.4)$ \\
\hline Currently not married & $17(23.6)$ \\
\hline \multicolumn{2}{|l|}{ Education } \\
\hline Illiterate & $10(14.3)$ \\
\hline Up to $10^{\text {th }}$ grade & $38(54.3)$ \\
\hline $10^{\text {th }}$ grade and above & $22(31.4)$ \\
\hline \multicolumn{2}{|l|}{ Employment status ${ }^{\dagger}$} \\
\hline Currently employed & $42(60.0)$ \\
\hline Not employed & $28(40.0)$ \\
\hline \multicolumn{2}{|l|}{ Family type } \\
\hline Nuclear & $47(65.3)$ \\
\hline Others & $25(34.7)$ \\
\hline Per-capita family income in Indian rupees per month & $2979( \pm 4441)$ \\
\hline
\end{tabular}

Table 2: Pathways of care

\begin{tabular}{lccc}
\hline Point of treatment & $\begin{array}{c}\text { Number of } \\
\text { patients with } \\
\text { first visit } \\
(\boldsymbol{n}=68)(\%)\end{array}$ & $\begin{array}{c}\text { Number of } \\
\text { patients with } \\
\text { any visit } \\
(\boldsymbol{n}=68)(\%)\end{array}$ & $\begin{array}{c}\text { As a source } \\
\text { of referral }^{\dagger} \\
(\boldsymbol{n}=\mathbf{4 7})(\%)\end{array}$ \\
\hline General practitioner & $42(61.8)$ & $49(72.1)$ & $3(6.4)$ \\
Other specialists & $22(32.4)$ & $65(95.6)$ & $41(87.2)$ \\
Traditional medicine & $4(5.9)$ & $25(36.8)$ & $2(4.3)$ \\
Other psychiatrists & - & $14(20.6)$ & $1(2.1)$ \\
\hline
\end{tabular}

21 patients were self-referred or came on the suggestion of family/friends

The patients had a median of 19 visits (inter-quartile range [IQR] of 9-30 visits) to various care providers over a median period of 24 months (IQR 12-84 months), before being evaluated in the department of psychiatry. The index contact was with a general practitioner in the majority of the cases $(61.8 \%)$ though a substantial proportion of the patients (32.4\%) had visited specialists at the first contact. A large majority of the patients (95.6\%) had visited specialists at some point of time before seeking treatment at the center. The source of referral to the Psychiatry Department was the patient himself/ herself or family/friends in 21 patients (30.88\%).

\section{Clinical features}

Somatoform group of disorders constituted the most common diagnosis in the sample $(n=36,50.0 \%)$, followed by depressive disorders $(n=22,30.6 \%)$ and anxiety spectrum disorders $(n=15,20.8 \%)$. The somatoform cluster could be further broken up into - undifferentiated somatoform disorder in 16, somatoform pain disorder in 10 , somatic-autonomic dysfunction in 4 , somatization disorder in 1 , and other somatoform disorder/somatoform 
disorder not otherwise specified in 5. About one-tenth of the sample $(n=8)$ had more than one psychiatric diagnosis while 2 patients ( $2.8 \%$ of the sample) had only physical disorders and no psychiatric disorders.

\section{Discussion}

\section{Challenges posed and opportunities provided by the clinic}

The present psychosomatic clinic, though in its infancy, provides some opportunities and highlights key challenges. The clinic provides convenience of services in a single location to patients with MUS, instead of being referred to different specialists for various aspects of care. In the current Indian scenario of human resource supply constraints, it is also scalable and can facilitate development of locally acceptable and efficacious models of care. A possible suggestion would be to train the physicians skilled in alternate systems of medicine who form a sizeable pool to manage these patients in primary care and vertically integrate them with such clinics in other higher centers. This may preempt visit to specialists unless deemed necessary. As far as tertiary Care Centers are concerned, offering care in a psychosomatic clinic may yield further opportunities for collaboration with medical and surgical specialists and de-stigmatize mental healthcare for these patients. The clinic provides opportunities for better training of healthcare personnel dealing with MUS patients. The psychiatry residents get wider exposure to the varied psychosomatic presentations, and treatment approaches used. At present, the clinic is involved in training psychiatry residents, but modules can be developed for the training of other health professionals in the future. Last, such a dedicated clinic may yield better and diverse research opportunities focusing on MUS.

Some of the challenges that have been experienced in running the clinic include first, the poor referral rates (1-2 patients/week) and second, convincing patients of the efficacy of psychological treatments for their problems. Third, as per locally prevalent cultural beliefs, patients expect some blood test and some tablets (and preferably colored injections and intravenous "glucose") to be given as a part of most treatments. As of present, advocating the efficacy of psychotherapeutic measures has been found to be challenging. Fourth, training modules need to be developed for more focused training of the residents and other professionals, emphasizing on communication and nonconfrontational approach toward patients with MUS.

To conclude, this psychosomatic clinic provided an opportunity for detailed evaluation of MUS patients.
It unlocks opportunities for inter-disciplinary cross talk and better dissemination of information about the special needs of people with MUS. There is very little systematic research output on psychosomatic disorders from developing countries, despite previous investigators reporting prevalence of psychosomatic symptoms among psychiatric populations comparable to that in the West. ${ }^{[16]}$ Other spinoffs included better training of psychiatry residents in a difficult area where clinicians are often wanting. Possible limitations of our clinic include its location in a tertiary care hospital setting, working with group concepts, and lumping together patients with different spectrum of diagnostic categories such as anxiety and depression for easier treatment logistics. Lack of dedicated in-patient beds and funding constraints are other limitations to its growth and expansion. The challenge for future healthcare researchers from developing countries such as India, where there is no pool of primary care physicians, is to develop cost-effective and culturally compatible models of care which vertically integrate the tertiary healthcare and primary healthcare systems for MUS patients. Such models may eventually take the locus of care away from specialists to the primary healthcare arena sparing much needed human resources. We hope this paper will provide practical insights to clinicians working with MUS, stem further research in this area and promote the development of more such clinics across the length and breadth of the country.

\section{Acknowledgments}

A preliminary version of this paper was presented as a research poster at the $67^{\text {th }}$ Annual National Conference of the Indian Psychiatric Society (ANCIPS 2015), Hyderabad from January $8^{\text {th }}$ to $11^{\text {th }}, 2015$.

\section{Financial support and sponsorship}

Nil.

\section{Conflicts of interest}

There are no conflicts of interest.

\section{References}

1. Burton C. Beyond somatisation: A review of the understanding and treatment of medically unexplained physical symptoms (MUPS). Br J Gen Pract 2003;53:231-9.

2. Kirmayer LJ. Mind and body as metaphors: Hidden values in biomedicine. In: Lock M, Gordon D, editors. Biomedicine Examined. Springer Netherlands; 1988. p. 57-93. Available from: http://www.link.springer. com/chapter/10.1007/978-94-009-2725-4_4. [Last cited on 2015 Aug 16].

3. Smith RC, Lein C, Collins C, Lyles JS, Given B, Dwamena FC, et al. Treating patients with medically unexplained symptoms in primary care. J Gen Intern Med 2003;18:478-89.

4. Hiller W, Fichter MM, Rief W. A controlled treatment study of somatoform disorders including analysis of healthcare utilization and 
cost-effectiveness. J Psychosom Res 2003;54:369-80.

5. Martin A, Rauh E, Fichter M, Rief W. A one-session treatment for patients suffering from medically unexplained symptoms in primary care: A randomized clinical trial. Psychosomatics 2007;48:294-303.

6. Barsky AJ, Ettner SL, Horsky J, Bates DW. Resource utilization of patients with hypochondriacal health anxiety and somatization. Med Care 2001;39:705-15

7. Koola MM, Kuttichira P. Psychosocioeconomic study of medically unexplained physical symptoms. Indian J Psychol Med 2012;34:159-63.

8. Kirmayer LJ, Groleau D, Looper KJ, Dao MD. Explaining medically unexplained symptoms. Can J Psychiatry 2004;49:663-72.

9. Singh S, Badaya S. Health care in rural India: A lack between need and feed. South Asian J Cancer 2014;3:143-4.

10. Parker R, Forrest L, Ward N, McCracken J, Cox D, Derrett J. How acceptable are primary health care nurse practitioners to Australian consumers? Collegian 2013;20:35-41.
11. Badrakalimuthu VR, Rangasamy Sathyavathy V. Mental health practice in private primary care in rural India: A survey of practitioners. World Psychiatry 2009;8:124-5.

12. Page LA, Wessely S. Medically unexplained symptoms: Exacerbating factors in the doctor-patient encounter. J R Soc Med 2003;96:223-7.

13. Edwards TM, Stern A, Clarke DD, Ivbijaro G, Kasney LM. The treatment of patients with medically unexplained symptoms in primary care: A review of the literature. Ment Health Fam Med 2010;7:209-21.

14. Rief W, Heitmüller AM, Reisberg K, Rüddel $\mathrm{H}$. Why reassurance fails in patients with unexplained symptoms - An experimental investigation of remembered probabilities. PLoS Med 2006;3:e269.

15. World Health Organization. The ICD-10 Classification of Mental and Behavioural Disorders: Clinical Description and Diagnostic Guidelines. Geneva: World Health Organization; 1992.

16. Chaturvedi SK, Michael A. Psychosomatic disorders in psychiatric patients in a developing country. Int J Soc Psychiatry 1988;34:123-9.

\section{Appendix 1}

The following questions are intended to assess your various points of contact with health care providers and source of referral before the current consultation. Please try to recollect and answer them as accurately as possible.

\begin{tabular}{l} 
Appendix 1: Questionnaire for assessing pathway of care in people with medically unexplained symptoms \\
\hline $\begin{array}{c}\text { Time of the first contact Number of contacts Index contact } \\
\text { (approximately) }\end{array}$ - Source of referral \\
with the source (tick the one below) (tick the one below)
\end{tabular}

Faith healer (approximately)

with the source

General allopathic practitioner

Traditional practitioner

Emergency services

Primary health care services

Nongovernmental organisations

Private mental health professionals

Tertiary care hospital services

Other tertiary care psychiatric services

None of the above (includes self-referrals and

referrals made by known relatives and other patients) 